\title{
Metal Specific Functionalized Nanofibers ${ }^{\dagger}$
}

\author{
Katri Laatikainen 1,*, Omoniyi Pereao ${ }^{2}$, Chris Bode-Aluko ${ }^{2}$, Guillaume Ndayambaje ${ }^{2}$ \\ and Leslie Petrik ${ }^{2}$ \\ 1 Laboratory of Computational and Process Engineering, Lappeenranta-Lahti University of Technology \\ LUT, P.O. Box 20, FI-53851 Lappeenranta, Finland \\ 2 Department of Chemistry, University of the Western Cape, Private Bag. X17, 7535 Bellville, South Africa; \\ pereaokola@gmail.com (O.P.); chrisbodealuko@gmail.com (C.B.-A.); ndayambajegu@gmail.com (G.N.); \\ lpetrik@uwc.ac.za (L.P.) \\ * Correspondence: katri.laatikainen@lut.fi; Tel.: +358505479970 \\ + Presented at the 15th International Symposium "Priorities of Chemistry for a Sustainable Development" \\ PRIOCHEM, Bucharest, Romania, 30th October-1st November 2019.
}

Published: 8 October 2019

Keywords: nanofiber; chelating ligand; polyacrylonitrile; polystyrene; polyethylene terephthalate; 2-(2'-pyridyl)imidazole; 2-pyridine amidoxime; diglycolic anhydride ligand; nickel; lead

Functionalized nanofibers made by electrospinning technique are one respectable option for metal removal and purification from aqueous solutions. Due to the simple and versatile process resulting in high porosity and high specific surface area structure with high selectivity properties, functionalized nanofibers have been gaining increased interest during recent decades [1]. In the case when high selectivity is needed, chelating ligand functionalized nanofibers are good option for the removal of heavy metals and rare earth elements (REEs) from aqueous solutions [2-3]. Chelating ligands act as electron donors and form coordinative bonds to a metal cation called the central atom, and, in this way, can increased significantly selectivity.

In our study, we have synthesized polyacrylonitrile (PAN) nanofibers with 2-(2'pyridyl)imidazole (pim) and 2-pyridine amidoxime (PyAMi) ligands for nickel and lead removal, respectively. Furthermore, we have also synthesized polystyrene (PS) and polyethylene terephthalate (PET) nanofibers with diglycolic anhydride ligand (DGA) and studied them for removal of the rare earth elements (REEs) $\mathrm{Ce}^{3+}$ and $\mathrm{Nd}^{3+}$ from aqueous solutions. All synthesized nanofibers were characterized for FTIR and BET specific surface areas, pore volumes, and average pore diameters. Chemical stabilities were studied in acidic conditions. Metals adsorption and binding kinetics were measured in batch system for all materials.

Metal adsorption capacities were in high level in all the materials. The case of PAN-pim, the nickel capacity at $\mathrm{pH} 5$ was $0.8 \mathrm{mmol} / \mathrm{g}$, whereas the lead capacity for PAN-PyAMI was at pH 60.025 $\mathrm{mmol} / \mathrm{g}$. In the case of REE removal, the binding capacities for PS-DGA and PET-DGA nanofibers for $\mathrm{Ce}^{3+}$ were 1.1 and $0.7 \mathrm{mmol} / \mathrm{g}$, respectively and for $\mathrm{Nd}^{3+}, 2.3$ and $0.5 \mathrm{mmol} / \mathrm{g}$, respectively. The binding kinetics of PS-DGA and PET-DGA for $\mathrm{Ce}^{3+}$ and $\mathrm{Nd}^{3+}$ were relatively fast-equilibria were attained for both REE over 20 and 5 min, respectively. The chemical stabilities of PS-DGA and PET-DGAs were good in acidic conditions, and metals were successfully regenerated from the nanofibers and reused at least four adsorption-desorption cycles without the loss of significant metal adsorption capacities. The adsorption rate of nickel for PAN-pim was extremely fast; the adsorption equilibrium was attained after 1 minute. However, chemical stability was not good. In the case of PAN-PyAMI, neither chemical stability nor adsorption rate for lead removal were good. 


\section{References}

1. Pereao, O.; Bode-Aluko, C.; Laatikainen, K.; Nechaev, A.; Petrik, L. A review of morphology, modification and characterization of electrospun polymer nanofiber adsorbent material used in metal ion removal. J. Polym. Environ. 2019, 27, 1843-1860.

2. Ndayambaje, G.; Laatikainen, K.; Laatikainen, M.; Beukes, E.; Fatoba, O.; van der Walt, N.; Petrik, L.; Sainio, T. Adsorption of nickel(II) on polyacrylonitrile nanofiber modified with 2-(2-pyridyl)imidazole. Chem. Eng. J. 2016, 284, 1106-1116.

3. Pereao, O.; Laatikainen, K.; Bode-Aluko, C.; Kochnev, Y.; Fatoba, O.; Nechaev, A.; Petrik, L. Adsorption of $\mathrm{Ce}^{3+}$ and $\mathrm{Nd}^{3+}$ by Diglycolic acid functionalised electrospun polystyrene nanofiber from aqueous solution. Sep. Purif. Technol. 2019, in Press.

(C) 2019 by the authors. Licensee MDPI, Basel, Switzerland. This article is an open access article distributed under the terms and conditions of the Creative Commons Attribution (CC BY) license (http://creativecommons.org/licenses/by/4.0/). 